\title{
Selective anticancer activity of hirsutine against HER2-positive breast cancer cells by inducing DNA damage
}

\author{
CHENGHUA LOU, SATORU YOKOYAMA, IKUO SAIKI and YOSHIHIRO HAYAKAWA \\ Division of Pathogenic Biochemistry, Department of Bioscience, Institute of Natural Medicine, \\ University of Toyama, Toyama, Toyama 930-0194, Japan
}

Received December 10, 2014; Accepted January 5, 2015

DOI: 10.3892/or.2015.3796

\begin{abstract}
Hirsutine is one of the major alkaloids isolated from plants of the Uncaria genus and is known for its cardioprotective, anti-hypertensive and anti-arrhythmic activities. We recently reported that hirsutine is an anti-metastatic phytochemical by targeting $\mathrm{NF}-\kappa \mathrm{B}$ activation in a murine breast cancer model. In the present study, we further examined the clinical utility of hirsutine against human breast cancer. Among six distinct human breast cancer cell lines, hirsutine showed strong cytotoxicity against HER2-positive/ p53-mutated MDA-MB-453 and BT474 cell lines. Conversely, HER2-negative/p53 wild-type MCF-7 and ZR-75-1 cell lines showed resistance against hirsutine-induced cytotoxicity. Hirsutine induced apoptotic cell death in the MDA-MB-453 cells, but not in the MCF-7 cells, through activation of caspases. Furthermore, hirsutine induced the DNA damage response in the MDA-MB-453 cells, but not in the MCF-7 cells, as highlighted by the upregulation of $\gamma \mathrm{H} 2 \mathrm{AX}$ expression. Along with the induction of the DNA damage response, the suppression of HER2, NF- $\kappa$ B and Akt pathways and the activation of the $\mathrm{p} 38$ MAPK pathway in the MDA-MB-453 cells were observed. Considering that there was no difference between MDA-MB453 and MCF-7 cells in regards to irinotecan-induced DNA damage response, our present results indicate the selective anticancer activity of hirsutine in HER2-positive breast cancer by inducing a DNA damage response.
\end{abstract}

\section{Introduction}

Breast cancer is the most commonly diagnosed cancer among women and is second only to lung cancer in terms of cancer-related mortality (1). Despite advances in breast cancer research and therapy, the mortality rate remains high (2);

Correspondence to: Dr Yoshihiro Hayakawa, Division of Pathogenic Biochemistry, Department of Bioscience, Institute of Natural Medicine, University of Toyama, Sugitani 2630, Toyama, Toyama 930-0194, Japan E-mail: haya@inm.u-toyama.ac.jp

Key words: breast cancer, HER2, apoptosis, DNA damage therefore, the development of new agents for breast cancer therapy is clinically important.

Phytochemicals are a promising source for the development of novel cancer therapeutics. Due to their potential effectiveness and low toxicity profiles (3), phytochemicals generally have been successful in clinical drug development to treat many diseases $(4,5)$. Hirsutine is one of the major alkaloids found in plants of the Uncaria genus and is known for its cardioprotective (6), anti-hypertensive and anti-arrhythmic activities (7). Recently, we identified hirsutine as an antimetastatic phytochemical by targeting NF- $\kappa \mathrm{B}$ activation in a murine breast cancer model. We demonstrated the significant anti-metastatic activity of hirsutine both in vitro and in vivo (8).

In the present study, we further explored the clinical utility of hirsutine against breast cancer by testing the effect of hirsutine against six human breast cancer cell lines. Notably, hirsutine showed selective anticancer activity against human breast cancer cell lines with HER2-expressing and p53-mutated phenotypes. We further identified that the induction of DNA damage response can be a primary target of hirsutine, leading to apoptotic cell death of breast cancer cells.

\section{Materials and methods}

Reagents. Hirsutine and a Cell Counting kit were purchased from Wako Pure Chemical Industries, Ltd. (Osaka, Japan). Muse Annexin V and Dead Cell Assay kits were purchased from EMD Millipore Corporation (Merck Millipore, Billerica, MA, USA). The reagent for the Caspase-Glo3/7 Assay was obtained from Promega (Madison, WI, USA). Irinotecan was purchased from Sigma-Aldrich (St. Louis, MO, USA).

Cells. All cell lines used in the present study were obtained from the American Type Culture Collection (ATCC). Human breast cancer cells ZR-75-1 and BT474 were maintained in RPMI-1640 medium containing $10 \%$ bovine serum (Nissui, Tokyo, Japan). MCF-7, MDA-MB-231, MDA-MB-468 and MDA-MB-453 cells were maintained in Dulbecco's modified Eagle's medium (DMEM) containing $10 \%$ bovine serum (Nissui). Cells were incubated at $37^{\circ} \mathrm{C}$ in a humidified atmosphere of $95 \%$ air and $5 \% \mathrm{CO}_{2}$.

Cell viability assay. For detection of the neoplastic activity of cells grown in 96-well plates, the human breast cancer cells 
in exponential growth were placed at a final concentration of $2 \times 10^{4}$ cells/well in a 96-well plate. After a 3 -h incubation, the cells were treated with hirsutine $(6.25,12.5,25$ and $50 \mu \mathrm{M})$ or with the vehicle (vehicle control, $0.5 \%$ DMSO) for $24 \mathrm{~h}$. After treatment, $10 \mu \mathrm{l}$ of WST-1 reagent was added. The microplate was incubated for another $2 \mathrm{~h}$ in a humidified atmosphere $\left(37^{\circ} \mathrm{C}, 5 \% \mathrm{CO}_{2}\right)$ to allow the formation of formazan dye and to get a higher sensitivity. The absorbance was measured in a microplate reader at 450/620 $\mathrm{nm}$. Cell viability was determined from the absorbance of soluble formazan dye generated by the living cells.

Detection of apoptosis. Cells were grown in 24-well plates and treated with $50 \mu \mathrm{M}$ of hirsutine for $15 \mathrm{~h}$ before assaying using Muse ${ }^{\mathrm{TM}}$ Cell Analyzer (Merck Millipore). Floating and adherent cells were collected after the treatments. The cells were washed twice with PBS and resuspended in PBS. The apoptosis profiling and apoptotic cell counts were obtained with Muse Annexin V and Dead Cell Assay kit. The assay was conducted in triplicate and in accordance with the manufacturer's instructions.

Measurement of caspase activity. For measurements of the activities of caspase- 3 and caspase-7, the Caspase-Glo ${ }^{\circledR}$ 3/7 Assay was carried out according to the manufacturer's instructions. This kit is based on the cleavage of the amino acid sequence DEVD of a luminogenic substrate by caspase-3 and caspase-7, which results in a luminescent signal. Human breast cancer cells in exponential growth were placed at a final concentration of $1 \times 10^{4}$ cells/well in $90 \mu \mathrm{l}$ in a white-walled multi-well plate. After $3 \mathrm{~h}$ of incubation, the cells were treated with hirsutine $(25$ and $50 \mu \mathrm{M})$ or with the vehicle (vehicle control, $0.5 \%$ DMSO) for another $3 \mathrm{~h}$. Then $100 \mu \mathrm{l}$ of Caspase-Glo ${ }^{\circledR} 3 / 7$ reagent was added, and the plates were incubated for another $30 \mathrm{~min}$. Caspase- 3 and -7 activities were recorded in a Glomax Multi-Detection system.

Western blot analysis. Cells were exposed to $50 \mu \mathrm{M}$ hirsutine for $0,1,3$ and $6 \mathrm{~h}$. Treated cells were collected, washed with PBS, and lysed in lysis buffer [25 mM HEPES (pH 7.7), 0.3 M $\mathrm{NaCl}, 1.5 \mathrm{mM} \mathrm{MgCl}_{2}, 0.2 \mathrm{mM}$ EDTA, 0.1\% Triton X-100, $20 \mathrm{mM} \beta$-glycerophosphate, $0.1 \mathrm{mM}$ sodium orthovanadate, $0.5 \mathrm{mM}$ phenylemethylsulfonyl fluoride (PMSF), $1 \mathrm{mM}$ dithiothreitol, $10 \mathrm{mg} / \mathrm{ml}$ aprotinin, and $10 \mathrm{mg} / \mathrm{ml}$ leupeptin]. The cell lysates were separated by 5-10\% SDS-PAGE and transferred to PVDF membranes using a glycine transfer buffer $[192 \mathrm{mM}$ glycine, $25 \mathrm{mM}$ Tris- $\mathrm{HCl}(\mathrm{pH} 8.8)$ and $20 \%$ (v/v) methanol]. After blocking with Block Ace for $4 \mathrm{~h}$ at room temperature, the membranes were incubated overnight with the primary antibodies, and then for $60 \mathrm{~min}$ with the secondary antibodies. Primary antibodies were used at a dilution of 1:1,000. The secondary antibodies were used at a dilution of 1:2,000 and visualized with an enhanced chemiluminescence system (Amersham Biosciences, Amersham, UK).

The following antibodies from Cell Signaling Technology (Danvers, MA, USA) were used for western blot analysis according to the manufacturer's recommendations: anti-phospho-Akt (Ser473, \#9271L), anti-phospho-p65 (Ser536, \#3033S); anti-caspase-3 (\#9662S), anti-phospho-p38 (p-p38) (Thr-180/Tyr-182, \#4511), anti-phospho-histone H2AX

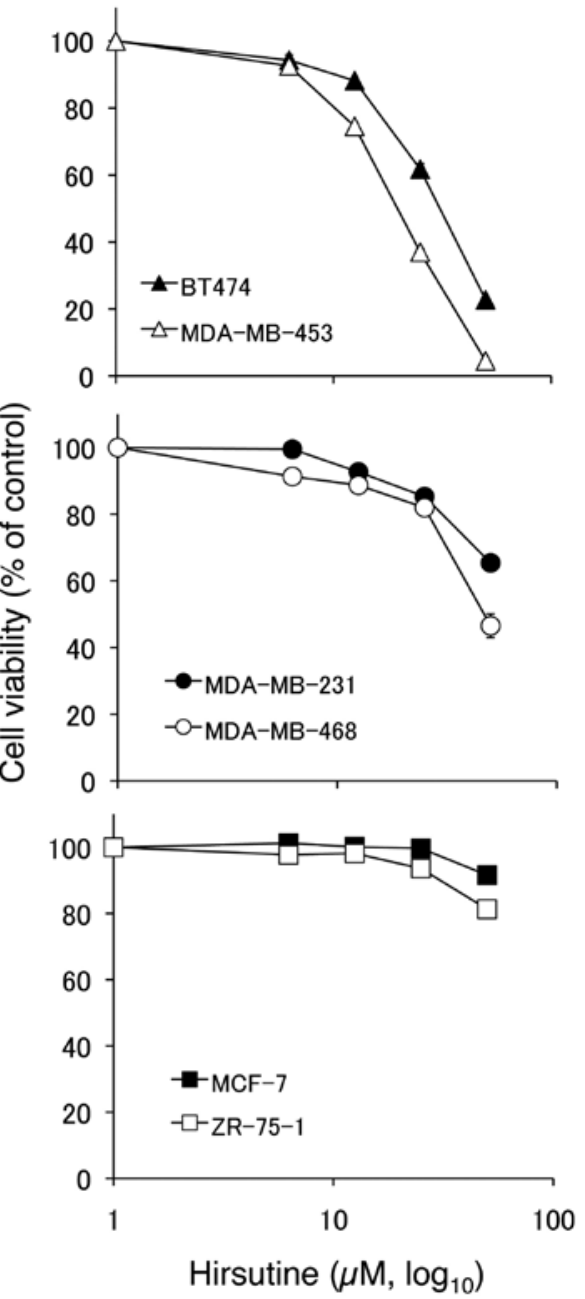

Figure 1. Selective cytotoxic effect of hirsutine on human breast cancer cell lines. Human breast cancer cells in exponential growth were placed at a final concentration of $2 \times 10^{4}$ cells/well in a 96-well plate and incubated for $3 \mathrm{~h}$. After incubation, the cells were treated with hirsutine $(6.25,12.5,25$ and $50 \mu \mathrm{M}$ ) or with the vehicle (vehicle control, $0.5 \%$ DMSO) for $24 \mathrm{~h}$. After treatment, $10 \mu \mathrm{l}$ of WST-1 reagent was added. The microplate was incubated for another $2 \mathrm{~h}$ to allow the formation of formazan dye and to obtain a higher sensitivity. The absorbance was measured in a microplate reader at $450 / 620 \mathrm{~nm}$. Cell viability was determined from the absorbance of soluble formazan dye generated by the living cells.

(Ser139, \#9947). Anti-actin (sc-1615, \#G1312), anti-caspase-9 (sc-7885, \#B0807), anti-ErbB2 (sc-284, \#L0706), anti-p65 (sc-109G, \#J1003), anti-Akt1 (sc-1618, \#131705) and anti-p38 $\alpha$ (sc-535, \#K1010) were purchased from Santa Cruz Biotechnology (Santa Cruz, CA, USA).

Statistical analysis. All the data are expressed as mean \pm SD of at least 3 independent experiments and were analyzed for statistical significance using the Student t-test. P-values $<0.05$ were considered statistically significant.

\section{Results}

Selective cytotoxicity of hirsutine against human breast cancer cells. We recently found hirsutine as an anti-metastatic phytochemical by targeting $\mathrm{NF}-\kappa \mathrm{B}$ activation in a murine breast cancer model. To further extend the utility of hirsutine, we examined the anticancer effect of hirsutine against human 


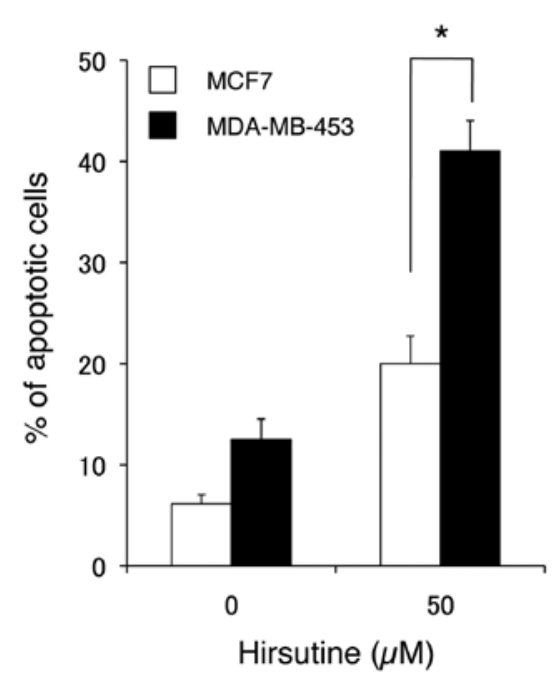

Figure 2. Effect of hirsutine on apoptotic cell death in the MDA-MB-453 and MCF-7 cells. MDA-MB-453 and MCF-7 cells were grown in 24-well plates and treated with $50 \mu \mathrm{M}$ of hirsutine for $15 \mathrm{~h}$ before assaying using the Muse $^{\mathrm{TM}}$ Cell Analyzer. Floating and adherent cells were collected after the treatments. Cells were washed twice with PBS and re-suspended in PBS. The apoptosis profiling and apoptotic cell counts were obtained with the Muse Annexin V and Dead Cell Assay kit. The assay was conducted in triplicate and in accordance to the manufacturer's instructions. ${ }^{*} \mathrm{P}<0.05$.

breast cancer cell lines with distinct molecular background. Among the 6 tested human breast cancer cell lines, hirsutine showed strong cytotoxicity against the MDA-MB-453 and BT474 cell lines that have HER2-positive and p53-mutated characteristics (Fig. 1, top panel). While triple-negative breast cancer cell lines MDA-MB-231 and MDA-MB-468 showed a moderate response (Fig. 1, middle panel), HER2-negative and p53 wild-type MCF-7 and ZR-75-1 cells showed significant resistance against hirsutine-induced cytotoxicity (Fig. 1, bottom panel).

Induction of breast cancer cell apoptosis by hirsutine. To examine whether the cytotoxic effect of hirsutine is a result of the induction of apoptosis, both hirsutine sensitive (MDA-MB-453) and resistant (MCF-7) cells were subjected to Annexin $\mathrm{V}$ staining $15 \mathrm{~h}$ after treatment with hirsutine. In concert with the hirsutine-induced cytotoxicity (Fig. 1), hirsutine significantly induced apoptosis in the MDA-MB-453 cells, but not in the MCF-7 cells (Fig. 2). Such induction of apoptosis by hirsutine was related to the activation of caspases, as noted in the elevated caspase-3/7 activity in the MDA-MB-453 cells, but not in the MCF-7 cells, $3 \mathrm{~h}$ after treatment with hirsutine (Fig. 3). This demonstrated that caspases played an important role in hirsutine-induced apoptosis in the MDA-MB-453 cells. These results clearly show that the induction of apoptotic cell death can be a potential mechanism for the selective anticancer effect of hirsutine against human breast cancer cells.

Hirsutine induces a DNA damage response in breast cancer cells. To further explore the possible mechanism of hirsutine to induce apoptosis in breast cancer cells, we assessed its effect on the MAPK, HER2, NF- $\mathrm{BB}$, and Akt signaling pathways, as well as the DNA damage response. As shown in Fig. 4, hirsutine significantly suppressed the HER2, NF- $\kappa B$, and Akt

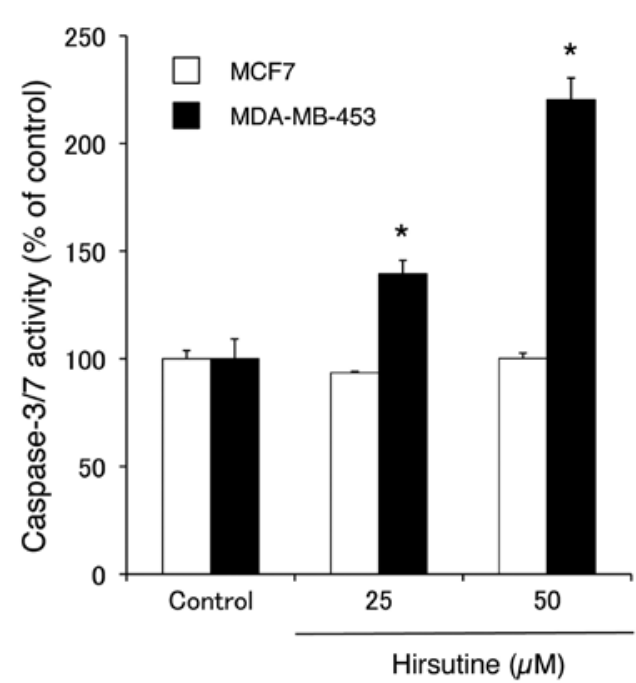

Figure 3. Effect of hirsutine on activities of caspases in the MDA-MB-453 and MCF-7 cells. The human breast cancer cells in exponential growth were placed at a final concentration of $1 \times 10^{4}$ cells/well in $90 \mu 1$ in a white-walled multi-well plate. After $3 \mathrm{~h}$ of incubation, the cells were treated with hirsutine (25 and $50 \mu \mathrm{M}$ ) or with the vehicle (vehicle control, $0.5 \%$ DMSO) for another $3 \mathrm{~h}$. Then $100 \mu \mathrm{l}$ of Caspase-Glo ${ }^{\circledR} 3 / 7$ reagent was added, and the plates were incubated for another $30 \mathrm{~min}$. Caspase-3 and -7 activities were recorded in a GloMax Multi Detection system. ${ }^{*} \mathrm{P}<0.05$.

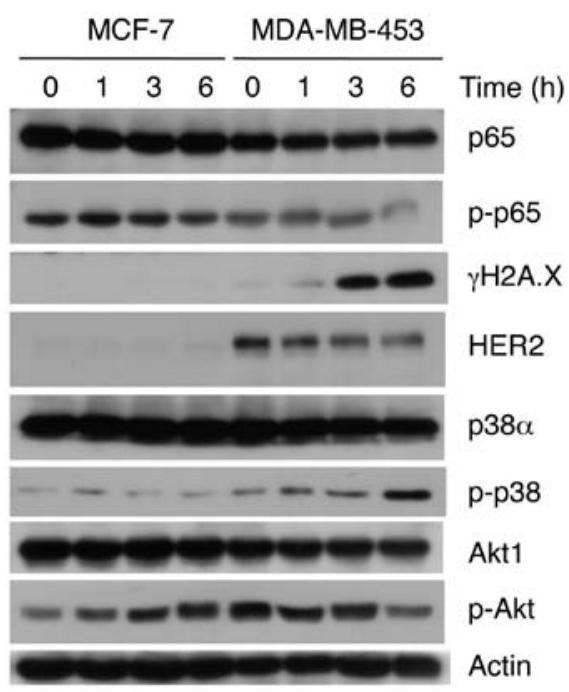

Figure 4. Effects of hirsutine on the DNA damage response in the MDA-MB-453 and MCF-7 cells. Cells were exposed to $50 \mu \mathrm{M}$ hirsutine for $0,1,3$ and $6 \mathrm{~h}$. Cell lysates were collected and subjected to western blot analysis to detect the expression of related proteins. Results are representative of at least 3 independent experiments showing similar results.

signaling pathways in the MDA-MB-453 cells. Meanwhile, the activation of the $\mathrm{p} 38$ MAPK stress pathway and a DNA damage response, as noted in the expression of p-p38 and $\gamma \mathrm{H} 2 \mathrm{AX}$, respectively, were observed upon hirsutine treatment in the MDA-MB- 453 cells. Conversely, hirsutine did not show any significant effect on those molecular pathways or DNA damage response in the MCF-7 cells. In order to determine the selectivity of hirsutine to induce the DNA damage response in HER2-positive and p53-mutant breast cancer cells, we used irinotecan as a typical DNA damage-inducing agent to assess its effects on the MCF-7 and MDA-MB-453 cells. As shown 


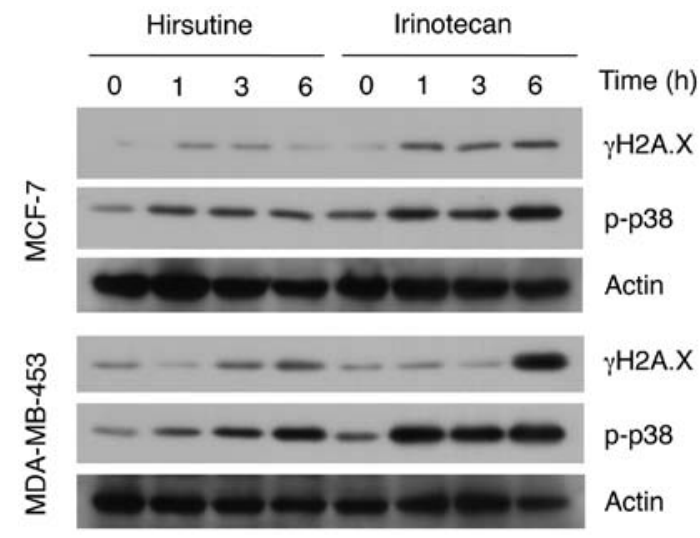

Figure 5. Selective activation of the DNA damage response by hirsutine in the MDA-MB-453 cells. Cells were exposed to hirsutine (50 $\mu \mathrm{M})$ and irinotecan $(400 \mu \mathrm{M})$ for $0,1,3$ and $6 \mathrm{~h}$. Cell lysates were collected and subjected to western blot analysis to detect the expression of p-p38 and $\gamma \mathrm{H} 2 \mathrm{AX}$ proteins in the MDA-MB-453 and MCF-7 cells. Results are representative of at least three independent experiments showing similar results.

in Fig. 5, irinotecan significantly upregulated $\gamma \mathrm{H} 2 \mathrm{AX}$ and p-p38 expression in both the MCF-7 and MDA-MB-453 cells, in contrast to hirsutine. Collectively, these results suggest the selective activity of hirsutine to induce DNA damage response in HER2-positive and the p53-mutated human breast cancer cells.

\section{Discussion}

In the present study, we investigated the clinical utility of hirsutine, an indol alkaloid phytochemical compound present in plants of the Uncaria genus, as an anticancer agent for human breast cancer cells. We found that the HER2-positive/ p53-mutated MDA-MB-453 and BT474 cell lines were relatively sensitive to hirsutine-induced cytotoxicity among the 6 tested human breast cancer cell lines (Fig. 1). To exert its cytotoxic activity against breast cancer cells, hirsutine induced apoptosis along with the activation of caspases (Figs. 2 and 3). Importantly, the expression of $\gamma \mathrm{H} 2 \mathrm{AX}$, a hallmark of DNA damage response, was significantly upregulated after treatment of hirsutine along with the p38/MAPK stress signaling pathways (Figs. 4 and 5) implying that a DNA damage response was involved in the hirsutine-induced apoptosis.

Apoptosis is a programmed cell death occurring in multicellular organisms (9). In general, drug-induced apoptosis is one major mechanism of action for treating cancer, and various signaling pathways are involved in the process (10). Among these, a DNA damage response is one of the molecular events leading to apoptosis, and indeed many anticancer agents induce a DNA damage response (11-15). The mechanism involved in DNA damage-induced apoptotic cell death is known to closely correlate with the DNA repair response (16-18). The phosphorylation of the Ser-139 residue of the histone variant $\mathrm{H} 2 \mathrm{AX}$, forming $\gamma \mathrm{H} 2 \mathrm{AX}$, is known as an early cellular response associated with the induction of DNA double-strand breaks. Therefore, induction of $\gamma \mathrm{H} 2 \mathrm{AX}$ has been considered as a hallmark of a DNA damage response (19-22). We originally identified hirsutine to inhibit $\mathrm{NF}-\kappa \mathrm{B}$ activation (8), and the NF- $\kappa \mathrm{B}$ pathway is known to play an important role in cancer progression (23-30). The NF- $\mathrm{KB}$ pathway can be activated as part of the DNA damage response by orchestrating cellular survival pathways $(31,32)$. Indeed, we observed the downregulation of p-p65 in the MDA-MB-453 cells, but not in the MCF-7 cells, in response to hirsutine treatment along with the inhibition of Akt activity (Fig. 4), which has been widely recognized as an important determinant for DNA damage-induced apoptosis $(33,34)$ and double-strand break repair (35-37). Considering the upregulation of $\mathrm{p}-\mathrm{Akt}$ in MCF-7 cells following hirsutine treatment along with resistance to its cytotoxicity, the NF- $\kappa \mathrm{B} / \mathrm{Akt}$ pathway may be involved in the selective resistance of MCF-7 cells against hirsutine.

In addition to the NF- $\mathrm{kB} / \mathrm{Akt}$ pathway, $\mathrm{p} 38$ MAPK activity is also known to play an important role in the DNA damage response induced by genotoxic stress with DNA-damaging chemotherapeutic agents through the activation of p53 (38). Inhibition of the p38 MAPK pathway reduced $\gamma \mathrm{H} 2 \mathrm{AX}$ expression (39), diminished the apoptotic fraction of cells and increased cell survival following exposure to chemotherapeutic agents $(15,38,40)$, thus suggesting a role for $\mathrm{p} 38$ activation in the apoptotic response against genotoxic stress. Consistently, we observed the upregulation of p-p38 upon hirsutine treatment in the MDA-MB-453 cells, but not in the MCF-7 cells. In the context of selective cytotoxicity, hirsutine treatment downregulated the expression of HER2 in the MDA-MB-453 cells (Fig. 4), which has been known to be involved in the repair response of DNA damage induced by chemotherapeutic agents $(41,42)$. Importantly, we obtained similar results of the DNA damage response in HER2-positive BT474 cells (data not shown). Furthermore, by using the anticancer drug irinotecan (CPT-11), which is a topoisomerase I inhibitor (43-47), we did not observe a selective induction of DNA damage response between the MDA-MB-453 and MCF-7 cells (Fig. 5). Considering the differential status of HER2 expression and/ or p53 mutation between the MDA-MB-453 and MCF-7 cells (48-50), HER2 expression and/or p53 status is presumably involved in determining the cellular response to hirsutine treatment. Although further study is clearly required to determine the exact mechanisms of action by which hirsutine targets cancer cells, our present study clearly demonstrated the selective anticancer activity of hirsutine against HER2-positive breast cancer cells by inducing DNA damage, implying its clinical utility as a novel anticancer drug.

\section{Acknowledgements}

This research was supported by a Grant-in-Aid for the 2012 and 2013 Cooperative Research Project I from the Institute of Natural Medicine, University of Toyama. C.L. is a graduate student supported by the Campus Asian Program of the University of Toyama.

\section{References}

1. DeSantis C, Ma J, Bryan L and Jemal A: Breast cancer statistics, 2013. CA Cancer J Clin 64: 52-62, 2014

2. Siegel R, Naishadham D and Jemal A: Cancer statistics, 2013. CA Cancer J Clin 63: 11-30, 2013.

3. Crowell JA: The chemopreventive agent development research program in the Division of Cancer Prevention of the US National Cancer Institute: an overview. Eur J Cancer 41: 1889-1910, 2005. 
4. Cragg GM, Newman DJ and Snader KM: Natural products in drug discovery and development. J Natl Prod 60: 52-60, 1997.

5. Harvey AL: Natural products in drug discovery. Drug Discov Today 13: 894-901, 2008

6. Wu LX, Gu XF, Zhu YC and Zhu YZ: Protective effects of novel single compound, hirsutine on hypoxic neonatal rat cardiomyocytes. Eur J Pharmacol 650: 290-297, 2011.

7. Horie S, Yano S, Aimi N, Sakai S and Watanabe K: Effects of hirsutine, an antihypertensive indole alkaloid from Uncaria rhynchophylla, on intracellular calcium in rat thoracic aorta. Life Sci 50: 491-498, 1992

8. Lou C, Takahashi K, Irimura T, Saiki I and Hayakawa Y: Identification of hirsutine as an anti-metastatic phytochemical by targeting NF- $\kappa \mathrm{B}$ activation. Int J Oncol 45: 2085-2091, 2014.

9. Elmore S: Apoptosis: a review of programmed cell death. Toxicol Pathol 35: 495-516, 2007.

10. Saddoughi SA, Song P and Ogretmen B: Roles of bioactive sphingolipids in cancer biology and therapeutics. Subcell Biochem 49: 413-440, 2008

11. Zhu H, Huang M, Yang F, et al: R16, a novel amonafide analogue, induces apoptosis and G2-M arrest via poisoning topoisomerase II. Mol Cancer Ther 6: 484-495, 2007.

12. Cai Y, Lu J, Miao Z, Lin L and Ding J: Reactive oxygen species contribute to cell killing and P-glycoprotein downregulation by salvicine in multidrug resistant K562/A02 cells. Cancer Biol Ther 6: 1794-1799, 2007.

13. Cai B, Lyu H, Huang J, et al: Combination of bendamustine and entinostat synergistically inhibits proliferation of multiple myeloma cells via induction of apoptosis and DNA damage response. Cancer Lett 335: 343-350, 2013.

14. Kudoh T, Kimura J, Lu ZG, Miki Y and Yoshida K: D4S234E, a novel p53-responsive gene, induces apoptosis in response to DNA damage. Exp Cell Res 316: 2849-2858, 2010.

15. Rudolf E, Kralova V, Rudolf K and John S: The role of p38 in irinotecan-induced DNA damage and apoptosis of colon cancer cells. Mutat Res 741-742: 27-34, 2013.

16. Norbury CJ and Zhivotovsky B: DNA damage-induced apoptosis Oncogene 23: 2797-2808, 2004.

17. Ljungman M: The DNA damage response - repair or despair? Environ Mol Mutagen 51: 879-889, 2010.

18. Roos WP and Kaina B: DNA damage-induced cell death by apoptosis. Trends Mol Med 12: 440-450, 2006

19. Mah LJ, El-Osta A and Karagiannis TC: gammaH2AX a sensitive molecular marker of DNA damage and repair Leukemia 24: 679-686, 2010.

20. Valdiglesias V, Giunta S, Fenech M, Neri M and Bonassi S $\gamma \mathrm{H} 2 \mathrm{AX}$ as a marker of DNA double strand breaks and genomic instability in human population studies. Mutat Res 753: 24-40, 2013.

21. Redon CE, Nakamura AJ,Zhang YW, et al: Histone gammaH2AX and poly(ADP-ribose) as clinical pharmacodynamic biomarkers. Clin Cancer Res 16: 4532-4542, 2010.

22. Ivashkevich AN, Martin OA, Smith AJ, et al: $\gamma \mathrm{H} 2 \mathrm{AX}$ foci as a measure of DNA damage: a computational approach to automatic analysis. Mutat Res 711: 49-60, 2011.

23. Xiao $\mathrm{G}$ and $\mathrm{Fu} \mathrm{J}$ : NF- $\mathrm{KB}$ and cancer: a paradigm of Yin-Yang. Am J Cancer Res 1: 192-221, 2011.

24. Basseres DS and Baldwin AS: Nuclear factor-kappaB and inhibitor of kappaB kinase pathways in oncogenic initiation and progression. Oncogene 25: 6817-6830, 2006.

25. Bours V, Bonizzi G, Bentires-Alj M, et al: NF-kappaB activation in response to toxical and therapeutical agents: role in inflammation and cancer treatment. Toxicology 153: 27-38, 2000.

26. Huang CY, Fong YC, Lee CY, et al: CCL5 increases lung cancer migration via PI3K, Akt and NF-kappaB pathways. Biochem Pharmacol 77: 794-803, 2009.

27. Nottingham LK, Yan CH, Yang X, et al: Aberrant IKKa and IKK $\beta$ cooperatively activate NF- $\kappa \mathrm{B}$ and induce EGFR/AP1 signaling to promote survival and migration of head and neck cancer. Oncogene 33: 1135-1147, 2014

28. Zhang W, Tan W, Wu X, et al: A NIK-IKK $\alpha$ module expands ErbB2-induced tumor-initiating cells by stimulating nuclear export of p27/Kip1. Cancer Cell 23: 647-659, 2013.

29. Ryan KM, Ernst MK, Rice NR and Vousden KH: Role of NF-kappaB in p53-mediated programmed cell death. Nature 404 $892-897,2000$
30. Kaltschmidt B, Kaltschmidt C, Hofmann TG, Hehner SP, Droge W and Schmitz ML: The pro- or anti-apoptotic function of NF-kappaB is determined by the nature of the apoptotic stimulus. Eur J Biochem 267: 3828-3835, 2000.

31. Janssens S and Tschopp J: Signals from within: the DNA-damage-induced NF-kappaB response. Cell Death Differ 13: 773-784, 2006.

32. Volcic M, Karl S, Baumann B, et al: NF- $\kappa$ B regulates DNA double-strand break repair in conjunction with BRCA1-CtIP complexes. Nucleic Acids Res 40: 181-195, 2012.

33. Kandel ES, Skeen J, Majewski N, et al: Activation of Akt/protein kinase B overcomes a G(2)/m cell cycle checkpoint induced by DNA damage. Mol Cell Biol 22: 7831-7841, 2002.

34. Henry MK, Lynch JT, Eapen AK and Quelle FW: DNA damage-induced cell-cycle arrest of hematopoietic cells is overridden by activation of the PI-3 kinase/Akt signaling pathway. Blood 98: 834-841, 2001.

35. Toulany M, Kasten-Pisula U, Brammer I, et al: Blockage of epidermal growth factor receptor-phosphatidylinositol 3-kinase-AKT signaling increases radiosensitivity of K-RAS mutated human tumor cells in vitro by affecting DNA repair. Clin Cancer Res 12: 4119-4126, 2006.

36. Toulany M, Kehlbach R, Florczak U, et al: Targeting of AKT1 enhances radiation toxicity of human tumor cells by inhibiting DNA-PKcs-dependent DNA double-strand break repair. Mol Cancer Ther 7: 1772-1781, 2008.

37. Toulany M, Kehlbach R, Rodermann HP and Mozdarani H: Radiocontrast media affect radiation-induced DNA damage repair in vitro and in vivo by affecting Akt signalling. Radiother Oncol 94: 110-116, 2010.

38. Sanchez-Prieto R, Rojas JM, Taya Y and Gutkind JS: A role for the p38 mitogen-activated protein kinase pathway in the transcriptional activation of $\mathrm{p} 53$ on genotoxic stress by chemotherapeutic agents. Cancer Res 60: 2464-2472, 2000.

39. Lu C, Shi Y, Wang Z, et al: Serum starvation induces H2AX phosphorylation to regulate apoptosis via p38 MAPK pathway. FEBS Lett 582: 2703-2708, 2008.

40. Bulavin DV, Saito S, Hollander MC, et al: Phosphorylation of human $\mathrm{p} 53$ by p38 kinase coordinates $\mathrm{N}$-terminal phosphorylation and apoptosis in response to UV radiation. EMBO J 18: 6845-6854, 1999.

41. Madson JG, Lynch DT, Svoboda J, et al: Erbb2 suppresses DNA damage-induced checkpoint activation and UV-induced mouse skin tumorigenesis. Am J Pathol 174: 2357-2366, 2009.

42. Boone JJ, Bhosle J, Tilby MJ, Hartley JA and Hochhauser D: Involvement of the HER2 pathway in repair of DNA damage produced by chemotherapeutic agents. Mol Cancer Ther 8: 3015-3023, 2009.

43. Wasserman E, Sutherland W and Cvitkovic E: Irinotecan plus oxaliplatin: a promising combination for advanced colorectal cancer. Clin Colorectal Cancer 1: 149-153, 2001

44. Ikeda M, Kurebayashi J, Sonoo H, et al: Evaluation of irinotecan hydrochloride (CPT-11) and trastuzumab combination therapy as salvage treatment in patients with HER2 overexpressing metastatic breast cancer. Gan To Kagaku Ryoho 36: 773-777, 2009 (In Japanese).

45. Anders C, Deal AM, Abramson V, et al: TBCRC 018: phase II study of iniparib in combination with irinotecan to treat progressive triple negative breast cancer brain metastases. Breast Cancer Res Treat 146: 557-566, 2014.

46. Chen AY and Liu LF: DNA topoisomerases: essential enzymes and lethal targets. Annu Rev Pharmacol Toxicol 34: 191-218, 1994.

47. Pommier Y: Eukaryotic DNA topoisomerase I: genome gatekeeper and its intruders, camptothecins. Semin Oncol 23: 3-10, 1996.

48. Neve RM, Chin K, Fridlyand J, et al: A collection of breast cancer cell lines for the study of functionally distinct cancer subtypes. Cancer Cell 10: 515-527, 2006.

49. Holliday DL and Speirs V: Choosing the right cell line for breast cancer research. Breast Cancer Res 13: 215, 2011.

50. Hermanto U, Zong CS and Wang LH: ErbB2-overexpressing human mammary carcinoma cells display an increased requirement for the phosphatidylinositol 3-kinase signaling pathway in anchorage-independent growth. Oncogene 20: 7551-7562, 2001. 